\title{
Therapeutic Plasma Exchange in Guillain Barre Syndrome: An experience of Bangabanhu Sheikh Mujib Medical University, Bangladesh
}

\author{
Sheikh Saiful Islam, Jannatul Ferdous, Ashraful Hoque, and Atiar Rahman
}

\section{ABSTRACT}

\begin{abstract}
Background: Therapeutic plasma exchange (TPE) has been used as one of the treatment modalities of neurological diseases. Intravenous Immunoglobulin (IVIG) and Therapeutic Plasma Exchange (TPE)are treatment options in Guillain Barre syndrome (GBS). In developing countries IVIG is not easily available and it is also expensive, TPE is preferred for treatment of GBS as it is affordable. Study on TPE for GBS are scarce here. Most of the study regarding TPE in GBS has been conducted in high -income countries as it is expensive treatment modality. Reports on TPE in GBS is very scared from Bangladesh.
\end{abstract}

Materials and Methods: A retrospective analysis of TPE with a standard hemolysis equipment for the treatment of Guillain Barre syndrome (GBS) was conducted A 50 patients of GBS who received TPE conducted between January 2017 to December 2018 in the department of Transfusion Medicine, Bangabandhu Sheikh Mujib Medical University, Dhaka, Bangladesh were analyzed. All patients had underdone at least 2 cycles of plasma exchange. Volume exchanged in each cycle was one plasma volume.

Results: Out of 50 cases there were $43(86 \%)$ male and 7 (14\%) female. Age range of patients was from 11 - 50 years. Approximately $40 \%$ improved clinically of first cycle of PE \& $85 \%$ after second cycle, $95 \%$ after third cycle and $95-100 \%$ after 5 cycle. $1(2 \%)$ patient died, and $49(98 \%)$ patients survived and recovered.

Conclusion: The treatment is cost affection in Compassion to IVIG. TPE is and affection, safe and affordable treatment modality for GBS.

Keywords: Guillain Barre Syndrome, immunoglobulin, plasma exchange.
Submitted : June 15, 2021

Published : January 5, 2022

ISSN: 2593-8339

DOI: $10.24018 /$ ejmed.2022.4.1.937

\section{S. S. Islam*}

Department of Blood Transfusion, BSMMU, Dhaka, Bangladesh.

(e-mail: drskshaheen@yahoo.com) J. Ferdous

Department of Obstetrics \& Gynecology, Dhaka Medical College Hospital, Dhaka, Bangladesh.

(e-mail: jannatjimc5@gmail.com) A. Hoque

Department of Blood Transfusion,

Sheikh, Hasina National Institute of

Burn Plastic Surgery, Dhaka,

Bangladesh.

(e-mail: ashraf.djmc03@gmail.com)

A. Rahman

Department of Blood Transfusion, BSMMU, Dhaka, Bangladesh.

(e-mail: atiar_ras@yahoo.com)

*Corresponding Author

\section{INTRODUCTION}

Guillain Barre syndrome (GBS) is sub-acute inflammatory demyelinating polyneuropathy may be succeeded to sever quadriparesis \& respiratory failure which may require ventilation. Approximately $20 \%$ of patients needed ventilation [1], [2].

Approximately one third of the patients with GBS will require mechanical ventilation and most GBS related death is due to respiratory failure [3]. The annual incidence of GBS is $0.4-4$ per 100,000 in the world. Men are more frequently affected than women [4].

GBS is an autoimmune disease of the peripheral nervous system. Campylobacter jejuni, cytomegalovirus, Epstein Barr virus and Mycoplasma pneumoniae may case GBS [5].

Molecular emulation between infectious agents and gangliosides plays a pivotal role [6].

Plasma exchange (PE) should be performed as early as possible in the course of GBS which may shorten the course and severity of GBS.

In plasma exchange there is withdrawing of the patient's blood, passing throw an instrument where different types of blood components are separated and returning all the cellular components (red cell, white cell \& platelets) along with either donor plasma and/or a manufactured replacement solution. Patient's plasma is collected in a plasma collection bag for removal. This is thought to rid the blood of substances that are attacking myelin of patient causing neuropathy [7].

High doses of intravenous Immunoglobin may be same helpful as plasmapheresis. There is also noted that although corticosteroid medication (such as prednisolone) is mainstay of anti-autoimmune disease treatment, are not only unhelpful, but may sometimes be harmful to patient with GBS [8].

\section{METHODS}

TPE in 50 GBS patients having age between 11-50 years was performed in Department of Transfusion Medicine, Bangabandhu Sheikh Mujib Medical University, Shahbag, Dhaka, Bangladesh during January 2017 to December 2018. Cobe spectra flow cell separator was used to perform plasma exchange of Guillan Barre syndrome.

Patients of GBS having Quadriparesis, difficulty in breathing and no bowel, bladder or any sensory involvement 
were included in this study. TPE was performed within seven days of diagnosis.

In each procedure, one volume of plasma was exchanged and FFP, sterile saline in combination with albumin was used as replacement fluid.

Two cycles of TPE were performed for each patient i.e., 2 cycles received by 50 GBS patients.

40 patients received 3 cycles and 5cycles were received by 25 GBS patients.

A femoral catheter was inserted in all patients before procedure.

Blood pressure, heart rate and heart rhythm were monitored clinically during the procedure.

Complications such as hypotension, nausea, vomiting dizziness, perioral tingling, abdominal pain was recorded during or immediately after procedure.

No fatal complication was observed. For tingling oral calcium, fluid for hypotension and intravenous calcium for abdominal pain was given as treatment.

\section{RESULtS}

TABLE I: DistRIBUTION OF PATIENTS By AGE

\begin{tabular}{ccc}
\hline \hline Age range (year) & Percentage (\%) & Frequency $(\mathrm{n})$ \\
\hline $11-20$ & 5 & 10 \\
$21-30$ & 28 & 56 \\
$31-40$ & 12 & 24 \\
$41-50$ & 5 & 10 \\
\hline \hline
\end{tabular}

TABLE II: DISTRIBUTION BY SEX

\begin{tabular}{ccc}
\hline \hline Sex & Frequency $(\mathrm{n})$ & Percentage $(\%)$ \\
\hline Male & 43 & 86 \\
Female & 7 & 14 \\
\hline \hline
\end{tabular}

TABLE III: COMPLICATIONS AND CLINICA IMPROVEMENT USING DIFFERENT CYCLES

\begin{tabular}{|c|c|c|c|}
\hline $\begin{array}{c}\text { Number of } \\
\text { cycles }\end{array}$ & $\begin{array}{c}\text { Number of } \\
\text { patients }\end{array}$ & $\begin{array}{c}\text { Complications } \\
\text { during procedure }\end{array}$ & $\begin{array}{c}\text { Clinical } \\
\text { Improvements }\end{array}$ \\
\hline \multirow[t]{3}{*}{ jor } & 40 & None & $\begin{array}{c}\text { More Than } \\
(40 \%)\end{array}$ \\
\hline & 10 & $\begin{array}{l}\text { Oral tingling } \\
\qquad(\mathrm{n}=7)\end{array}$ & $\begin{array}{l}\text { Abdominal } \\
\text { Pain }(n=3)\end{array}$ \\
\hline & 25 & $\begin{array}{c}\text { Hypotension } \\
(\mathrm{n}=3)\end{array}$ & $\begin{array}{c}\text { More than } \\
85 \%\end{array}$ \\
\hline \multirow{3}{*}{2} & 15 & Vomiting(n=2) & \\
\hline & 8 & Vomiting $(n=2)$ & \\
\hline & 2 & $\begin{array}{c}\text { Oral } \\
\text { tingling }(\mathrm{n}=1) \\
\end{array}$ & \\
\hline 3 & 40 & None & $\begin{array}{c}\text { More than } \\
95 \%\end{array}$ \\
\hline 5 & 25 & None & Almost $100 \%$ \\
\hline
\end{tabular}

TABLE IV: DISTRIBUTION BY SURVIVAL/RECOVERY

\begin{tabular}{ccc}
\hline \hline Death/recovery & Percentage (\%) & Frequency (n) \\
\hline Death & 1 & 2 \\
Recovery & 49 & 98 \\
\hline \hline
\end{tabular}

\section{DiscusSION}

Improvement of patients with GBS depends on fall of antibody titers by TPE. The pathogenic antibodies are not identified by TPE.

Plasma exchange $(\mathrm{PE})$ is a nonspecific procedure that removes all the non-formed substances in plasma including cytokines, immunoglobulins, and other serum factors.
Specific factor removal is crucial in therapeutically successful plasma exchange. There is data scarcity of plasma exchange effect on different diseases[12]-[14].

Results of this study were comparable to other studies for GBS.

Two or more cycles are more beneficial than one cycle.

Plasma exchange (PE)for GBS started early is more beneficial specially started within 7days of disease onset. It was also beneficial in patients treated up to 30days after the onset of disease.

Reference [15] performed a similar study on 6 patients with acute GBS. In that study all patients were report improved in motor strength as well as sensory symptoms. Before plasma exchange all patients were found to have high titer of immune complexes, which was reduced after plasma exchange which is in accordance with this study [15]. Similar study reports were shown by [16].

Plasma exchange is more beneficial if started within seven days of onset of GBS but may response within 30days of onset. The possible cause may be due to removal of complement dependent myelinotoxic antibodies [17].

Reports by [8] was similar in his review.

One cycle of plasma exchange with FFP as replacement fluid costs approximatelyTk.20000.00, with albumin and normal saline is around Tk.35000.00 and 1 dose of Intravenous Immunoglobulin (IVIG)is about Tk.1 Lac. So, plasma exchange (PE) is comparatively less expensive than Intravenous Immunoglobulin (IVIG).

Reference [7] in his review reported cost effectiveness of $\mathrm{PE}$ in intensive care unit (ICU) and hospital expenditure.

\section{CONCLUSION}

Therapeutic plasma exchange is an ideal treatment modality of Guillain Barre syndrome as it is found that the procedure is safe with negligible complication, and it is cost effective.

\section{REFERENCES}

[1] Doorn PAV, Ruts L, Jacob BC. Clinical feature,pathogenesis and treatment of Guillain Barre syndrome. Lancet Neurol .2008; 7: 939-50.

[2] Chevret S, Hughes RA, Annane D. Plasma exchange for Guillain-Barré syndrome. Cochrane Database Syst Rev. 2017; 2(2): CD001798.

[3] Zafar MS, Naqash MM, Bhat TAA, Malik GM.Guillain Barre sydrome in pregnancy:an unusual case. J Family Med Prim Care .2013; 2: 90-1.

[4] Huges RA, Rees JH. Clinical and epidemiologic features of Guillain Barre syndrome. J Infect Dis. 1997; 176(suppl 2): S92-8.

[5] Jacobs BC, Koga M, van Rijs W, Geleijns K, van Doorn PA, Willison $\mathrm{HJ}$, et al. Subclass IgG to motor gangliosides related to infection and clinical course in Guillain-Barré syndrome. J. Neuroimmunol. 2008; 194(1-2): 181-190.

[6] Perera VN,Nachamkin I,Ung H,Patterson JH,McConville MJ,Coloe PJ et al. Role of the lipo-oligosaccharide core oligosaccharide in inducing anti-ganglioside antibodies. FEMS Immunol MedMicrobial. 2007; 50: 27-36.

[7] Tharakan J, Ferner RE, Huges RAC, Winer J, Barnett M, Brown ER, et al. PE for Guillain Barre syndrome. J. Royal Soc Med. 1989; 82: 45861.

[8] Van MFGA. The Guillain Barre syndrome: plasma exchange or immunoglobulin intravenously. J Neurology NeurosurgPsych. 1994; 57: $33-4$.

[9] Durward WF, Burnett AAK, Watkins R, Reid JM. Plasma exchange in Guillain Barre syndrome. Br Med J.1981; 283(6294): 794.

[10] Gross ML, Legg NJ, Lockwood MC, Pallis C. The treatment of inflammatory polyneuropathy by plasma exchange. $J$ Neurol Neurosurg Psych. 1982; 45(8): 675-9. 
[11] Kennard C, Newland AC, Ridley A. Treatment of the Guillain Barre syndrome by plasma exchange. J Neurol Nerusurg Psych. 1982; 45(9): $847-50$.

[12] Brett RP, Gross M, Leggt NJ, Lockwood M, Pallis C. Treatment of acute polyneuropathy by plasma exchange. Lancet. 1978; 2(8099): 1100.

[13] Harakan J, Taandon M, Maheshwari MC. Plasmapheresis in acute infective polyneuritis. J Assoc Physicians India.1982; 30(3): 155-6.

[14] Sanchez AP, Balogun RA. Therapeutic Plasma Exchange in the Critically Ill Patient: Technology and Indications. Adv Chronic Kidney Dis. 2021; 28(1): 59-73.

[15] Vabonesi M, Garelli S, Mosconi L, Zerbi D, Celano I. Plasma exchange as a therapy for Guillain Barre syndrome with immune complexes. Vox Sang. $1981 ;$ 41(2): 74-8.

[16] Greenwood RJ, Newsom DJ, Huges RA, Aslan S, Bowden AN, Chadwick DW, et al. Controlled trial of plasma exchange in acute inflammatory polyneuropathy. Lancet.1984; 1(8382): 877-9.

[17] Rial D, Stark R, Swash M, Newland A. Improvement in nerve condition after plasma exchange for Guillain Barre syndrome. J Neurol Neuosurg Psychiatry. 1980; 43(12): 1147. 